\title{
Innovative Thinking Plays Important Role in Graphic Design
}

\author{
Yingying $\mathrm{Ma}$ \\ Qingdao Binhai University, Qingdao, 266555, China
}

Keywords: innovative thinking; graphic design; impact; content

\begin{abstract}
At present, we live in the information age which requires graphic design having innovative thinking that plays important role in improvement of capacity of graphic design. Hence, we should explore innovative thinking of graphic design, which has great significance for enhancing innovation capability and vitality of graphic design. Based on above situation, this article outlines relationship between innovative thinking and graphic design, states important significance of innovative thinking in graphic design, discusses major impact of innovative thinking in graphic design and analyzes the content of creative thinking in graphic design.
\end{abstract}

\section{Introduction}

Design is the general term of ideas and plans. According to design space situation, it can be classified into graphic design, three-dimensional design and space design, of which graphic design is the basic one. Through combined art with science make graphic design had aesthetic character and practical applicability. Generally speaking, the essence of graphic design is aesthetic creation with innovative implementation as foundation. Originality that guides the aesthetic creation implementation has the very important fundamental role in graphic design. Originality refers to consciousness of innovation of designers, which achieved by designers' innovative thinking. So we said, innovative thinking is the heart of originally and essence of graphic design.

\section{Relationship between Innovative Thinking and Graphic Design}

Innovative thinking is heart of graphic design and three-dimensional design. Design usually means a purposeful and thoughtful plan, which would be shown by graphic design and is an artistic form that has closely to specific purpose. In graphic design, we generally use visual element to express the designer's ideas and plans and make use of text and graphic to transfer the information to customers in order to allow people to understand our vision and plan. No innovative thinking means there is no connotation. That is to say, the whole process of design activity is process of formation of design work through design and conception from innovative thinking. Innovation focuses on discovery and creation, which is an essential attribute of graphic design. Significance of innovation lies in breaking current constraints to produce design conception through originality and novelty of the ideas or forms as well as to produce design thinking by handling design process and accumulation of perceptual data and applying corresponding thinking and imagination means to achieve rules processing. For design section, the formation of innovative thinking will improve designers' design capabilities. And yet accurate and scientific innovative thinking can promote development and progress of graphic design.

\section{Important Significance of Innovative Thinking in Graphic Design}

\subsection{Innovative thinking could help designers to improve innovation capability}

As one of the important aesthetic creation activities, the quality of graphic design is determined by designers' innovation capability. One should improve its innovation capability through development of innovative thinking to increase design effect. As one of mankind's unique aesthetic creative activity, graphic design requires of designers has innovative thinking method. In line with other art design, its essence lies in aesthetic creation. Only designers pay attention to training their innovative thinking and improve aesthetic innovation capability can real adapt to the aesthetic creation of this era. Creativity is the ability of people generally has. However, designers shall focus 
on how to improve their innovation. According to one study, enhancing designers' innovation could be realized by training designers' innovative thinking ability. Innovation include initiative and noninitiative. Yet the implementation of initiative of creation can become top 1 of artistic creation. Initiative usually generated from training designers' innovative thinking ability during practical activities instead of spontaneously formed.

\subsection{Innovative thinking can enhance originality and vitality of graphic design works}

Characteristic of graphic design determines the important meaning of innovative thinking in design. First, as a practical activity limited by time and space, the major works of graphic design will be marked with characteristics of a particular era inevitably. The designers shall enhance modern consciousness and innovation consciousness to break traditional thinking. Only being in an open pattern and training innovative thinking as well as breaking limitations of time and space can realize breakthrough in art, which could reduce the negative impact of limitations of time reasonably, thereby enhancing vitality of design works. Second, graphic design is innovation activity that meets certain requirements of modern people, which shall be implemented according to modern aesthetic of people. People also have different requirements that make designers shall use their innovative thinking to satisfy diversity of aesthetic demand. Third, graphic design is an innovation activity that is the essence of characteristics of graphic design in turn. Graphic design activity itself is a kind of aesthetic creation, which requires designers must have innovation spirit and innovation ability to make great effort to achievement.

\section{Major Impact of Innovative Thinking in Graphic Design}

The depth of design thinking becomes a key success in the graphic design works in a certain angle. In the course of teaching, we found that many works has strong sense of form and weak innovation. This phenomenon in the professional design was obvious, which may be caused by ignore the train of innovative thinking I think. Hence, the designers should consider several issues like how to train and apply innovative thinking; how to make the works with contemporary and aesthetic feeling; how to create works with creative; how to made works with meaningful form.

For understanding of the objective world, modern people usually have two different ways of thinking, that is, logical thinking and image thinking. The former is progressive linear thinking process, which uses abstract conceptualization of visualized content to form concept or theorem and realize expected purpose through abstract inference and judgment. While the later one mainly put specific image and representation of object as main content. It mainly uses the accumulation of specific image and abandons nonessential sensibility, then use imagination to deduce the typical image. It mainly puts image as materials and tools to create a character. Based on these means, it has nonlinear characteristics with non-continuity and jump. The main implication of design thinking is innovative thinking. If there is no innovative thinking, there is no graphic design. We should get rid of outdated and simplistic habits and constraints of personal intuition and study it by diversification of imaginary space to implement innovation in graphic design. We can learn and study it from a large number of outstanding creative thinking methods, for example, Dutch painter M. C. Escher's graphic design like man and the horse joining together, upward stairs but not really rise, two hands with different level and a drawing hand. Of which, there is one particularly interesting work that shows blackbirds fly out of ground and the surrounding gradually changes with flying height and finally it has white birds among blackbirds. M. C. Escher likes to use the technique of infinite repetition which just like fugue in music, fade away gradually but loop forever. We just like a bird constantly move freely in space debris. We want our works to bring fresh and special effects for customers and thinking method can bring us different visual response.

For quite a long time, the public has familiar with the application of ink painting in graphic design. In fact, this is a creative behavior for graphic designers, which not only has native consciousness, but linked with modern design. Many graphic designers rational implement ink painting in artistic designing that becomes a new creative point. As a consequence, this is a study with innovative thinking as starting point. To this end, because artistic designing could be viewed as combination culture and art with science and technology, the graphic design has a kind of 
irreversible inheritance significance. It is necessary to emphasize on traditional culture and positively cultivate traditional design with modern fashion style, which is one of excellent results of the elegantly union between creative thinking and graphic design.

\section{Analyze the Content of Creative Thinking in Graphic Design}

Innovative thinking mainly refers to the ability to break the conventional means to achieve innovative new form of thinking. The innovative thinking of graphic design works is a comprehensive application of different kinds of thinking form, which has essence of scientific thinking. It is a comprehensive embodiment between intuitive thinking and analytical thinking; divergent thinking and convergent thinking; abstract thinking and image thinking as well as reproductive imagination and inspiration thinking. Hence, innovative thinking in graphic design can be reflected in the following aspects:

First is intuitive thinking and analytical thinking. The later, also called logical thinking, should follow very strict logical rules and gradually deduce and implement to get final logical conclusion. The former with savvy primarily relies on people's intuition to identify problems, analyze problems, and solve problem. It has a premonition on significance and results of problem or situation to directly toward the target. The designers naturally combine the intuitive thinking with analytical thinking in graphic design. These two factors are contact each other and complement each other.

Second is divergent thinking and convergent thinking. The former expands ideas by thinking from many aspects. It is a new way of thinking for analyze problem from various aspects with draw inferences as key feature. This is why so many modern people select divergent thinking to solve problem and plays important role in innovative thinking. The latter, mainly based on traditional and single form to find accurate answers, focuses on in-depth exploration and research in some innovation process. Of course, these two factors have closely relationship in graphic design.

Third is abstract thinking and image thinking. In innovative thinking, the former, can be known as logical thinking, implemented by conception, judgment and logical form. Its main feature is that uses abstract conceptualization of visualized content to form concept, theorem and theory which made sublimate from sensibility to rationality on understanding of people and then from abstract to rationality. Image thinking shows the reality by visual image with special image and representation of object as main thinking form. If we use image thinking in graphic design, it usually made the work rich and vivid effect. According to research, there is no innovative thinking once abstract thinking ability and image thinking ability are both weak. Hence, the designers shall make full use of abstract thinking and image thinking to produce innovative thinking ability in order to make people satisfied with the works.

Fourth is creative imagination based on reproductive imagination. Associative thinking refers to perceptual imagination which is important basic thinking innovative artistic conception. The designers shall regularly adopt associative thinking and other thinking forms, for instance, combined the object and concept with different meaning as well as other factors without relationship. Just like when you see a cigarette, you will naturally want a ashtray. So does saddle and horse. Indeed, this explains the importance of associative thinking in creative thinking activities.

Fifth is inspiration thinking. This does not refer to a kind of accidental telepathy, but have produced by important object basis, which often needs a lot of induced factors. During graphic design, the designer is likely to be inspired by some objects or phenomenon to get a good work. So, inspiration thinking has an immeasurable role.

\section{Conclusion}

Overall, innovative thinking plays important role in graphic design and one of main indicators for judge and measure the importance of economic strength of a country or a region. Therefore, we should develop innovative thinking ability instead of study the formal language and pay attention to cultivate creative graphic design thinking and develop innovative capability by innovative thinking 
methods and means to create a perfect work.

\section{References}

[1] Qiao Yingjie. Brief Talk about Cultivate Creative Thinking in Graphic Design [J]. Liaocheng University Journal (Social Science Edition), 2010 (2).

[2] Kong Xiangyu. New Interpretation of Graphic Design Thinking in Postmodern Context [J]. Popular Literature, 2011 (4).

[3] Xu Xianbin. Divergent thinking in Graphic Design [J]. Popular Literature, 2012 (5).

[4] Rui Caihong. Exploration of Creative Thinking in Graphic Design [J]. Art Education Research, 2012 (21).

[5] Pan Xia. Deliberate Innovative Thinking in Graphic Advertisement Design [J]. Modern Decoration (Theory), 2013 (7).

[6] Zhoufen Fen. Discuss Creative Thinking in Graphic Design [J]. Packaging World, 2014 (1). 